\title{
Recurrence after polypectomy for a pedunculated polyp with subtle invasion but no unfavorable histology
}
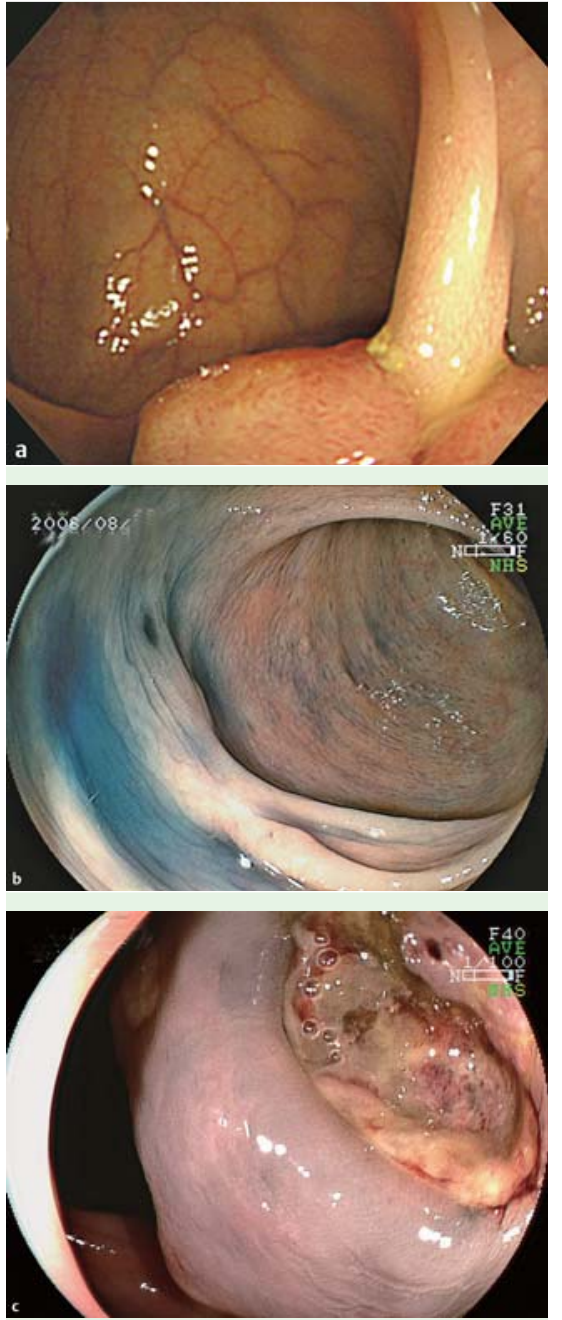

Fig. 1 Endoscopic findings of a large pedunculated polyp. a At presentation with a long thin stalk. b At follow-up, 1 year and 4 months later. c At repeat follow-up, 2 years and 8 months after presentation.

A 42-year-old male patient presented with hematochezia. Colonoscopy revealed an approximately 3-cm pedunculated polyp with a long stalk, at $14 \mathrm{~cm}$ from the anal verge. The head of the polyp had a multilobular appearance but no ulceration. The stalk was thin and smooth ( $\bullet$ Fig. 1 a). The lesion was resected using standard polypectomy techniques and retrieved in its entirety. Histology showed that the cut end of the stalk was completely negative, and one of the four sections demonstrated subtle invasion into the submucosal layer of the head of the polyp ( $\bullet$ Fig. 2a). Tumor
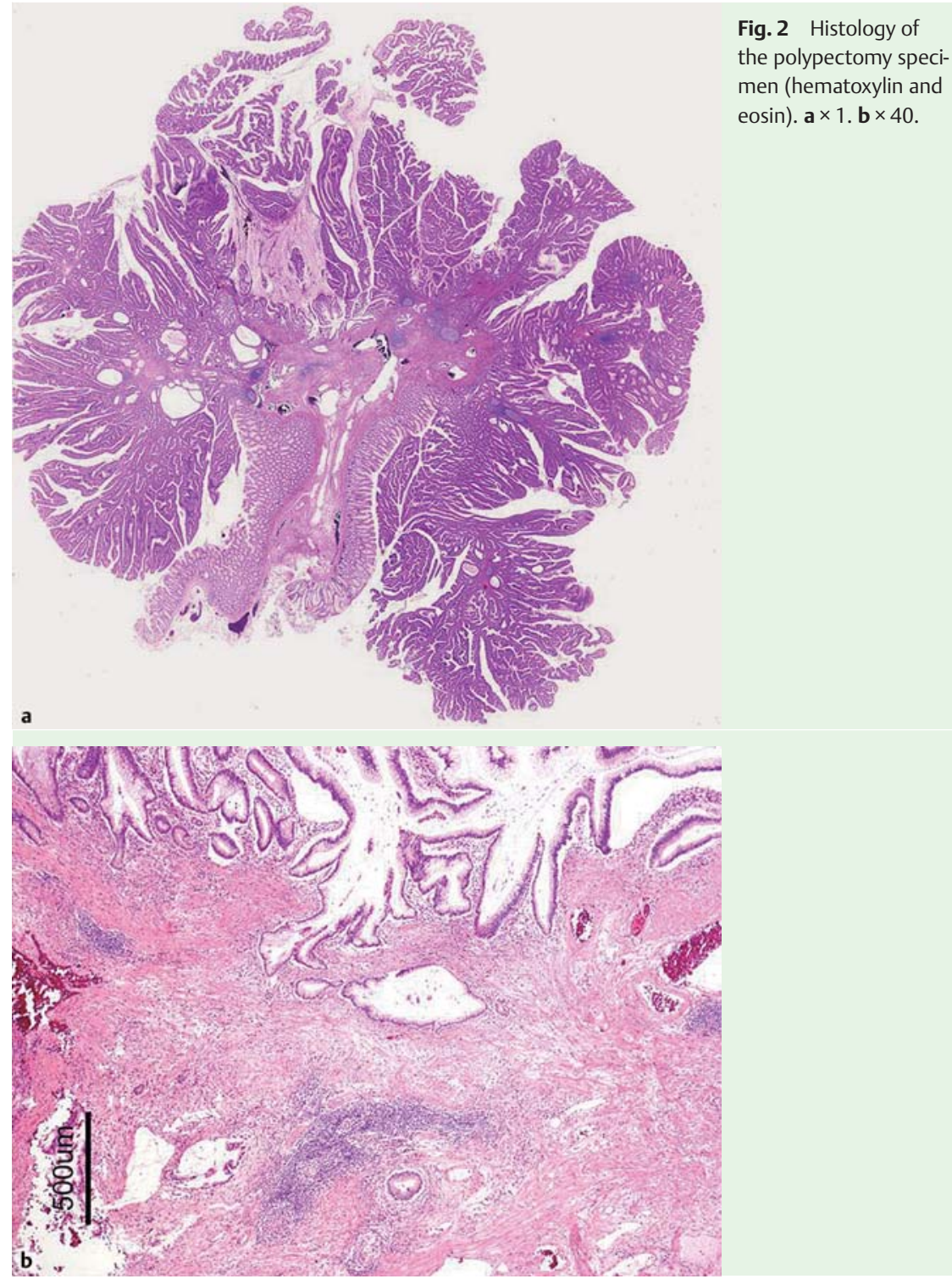

tumor with ulceration was detected at the polypectomy site, identified by the previous tattoo ( $\bullet$ Fig. 1 c). Surgical resection was then carried out, and the specimen showed pure mucinous adenocarcinoma, with pathologic T3N1 staging. The original paraffin-embedded specimen was cut further for immunohistochemistry studies. An expert pathologist reviewed the histologic findings. However, the present case did not possess any unfavorable histology [1-5].

To the best of our knowledge, this is the first description of a pedunculated polyp 
that was initially resected by endoscopy but relapsed as an advanced carcinoma despite lacking the usual indicators.

Colonoscopists should be aware of such a rare case of recurrence, which was unpredictable. Tattooing may be universally applicable for polypectomy sites with possible invasive cancers.

Endoscopy_UCTN_Code_CCL_1AD_2AB

Competing interests: None

K. Togashi ${ }^{1,2}$, Y. Ajioka ${ }^{3}$, K. Koinuma ${ }^{1}$, A. T. Lefor ${ }^{1}$, Y. Miyakura ${ }^{1}$, H. Horie ${ }^{1}$, Y. Yasuda ${ }^{1}$

1 Department of Surgery, Jichi Medical University, Tochigi, Japan

2 Department of Endoscopy, Jichi Medical University, Tochigi, Japan

3 Division of Molecular and Diagnostic Pathology, Niigata University, Niigata, Japan

\section{References}

1 Cranley JP, Petras RE, Carey WD et al. When is endoscopic polypectomy adequate therapy for colonic polyps containing invasive carcinoma? Gastroenterology 1986; 91: 419-427

2 Cooper HS, Deppisch LM, Gourley WK et al. Endoscopically removed malignant colorectal polyps: clinicopathologic correlations. Gastroenterology 1995; 108: 1657-1665

3 Whitlow C, Gathright JB Jr, Hebert SJ et al. Long-term survival after treatment of malignant colonic polyps. Dis Colon Rectum 1997; 40: 929-934

4 Netzer P, Forster C, Biral R et al. Risk factor assessment of endoscopically removed malignant colorectal polyps. Gut 1998; 43: 669674

5 Ueno H, Mochizuki H, Hashiguchi Y et al. Risk factors for an adverse outcome in early invasive colorectal carcinoma. Gastroenterology 2004; 127: 385 - 394

\section{Bibliography}

DOI $10.1055 / \mathrm{s}-0029-1215373$

Endoscopy 2011; 43: E38 - E39

(c) Georg Thieme Verlag KG Stuttgart · New York . ISSN 0013-726X

\section{Corresponding author}

\section{K. Togashi, MD, PhD}

Department of Endoscopy jichi Medical University 3311-1 Yakushiji

Shimotsuke Tochigi 329-0498

Japan

Fax: +81-285443234

ktogashi@jichi.ac.jp 